\title{
Consumer Perception towards Localization of MNC Fast Food Chain in Pakistan
}

\author{
Mehwish Channa, Adnan Pitafi, Ghazala Tunio \\ MUISTD, MUET, Jamshoro,Sindh, Pakistan. \\ mehwishchanna.1447@gmail.com, adnan.pitafi@faculty.muet.edu.pk, \\ ghazala.tunio@faculty.muet.edu.pk
}

\begin{abstract}
The study tests the consumer preferences in Pakistan (a developing economy) to know about the consumer's choice and localization of MNC to have clear understanding of entering in to the new market following the local culture of the country. Study focuses on the multinational fast food outlets. The research is grounded on both primary \& secondary information and primary data is collected randomly from 412 fast food consumers through closed ended questionnaire and analyzed through simple percentage analysis and SPSS to know about the relationship with different factors like, location, Quality, consumer satisfaction and preferences. Findings show that consumer's choice is influenced by quality, price as well as location. Study also shows that McDonalds is a high quality restaurant according to the consumers perception and more expensive than any other MNC outlet in Pakistan, consumers prefer to visit KFC and McDonalds frequently the consumers in Pakistan prefer food with the price conscious attitude. The main thing for the fast food restaurants is the food which is served quickly and finds it more advantageous. According to this study location accessibility is also a motive for consumers when they choose a particular outlet, closer restaurants are more numerous for easy take away.
\end{abstract}

Keywords: Consumer preferences, pricing, fast food products, MNC, Localization

\section{Introduction}

Restaurants are critical to any country's economic development, and the fast food business has grown to be one of the world's most significant developing industries (Baldwin, 2018; Goyal \& Singh, 2007). According to a multidimensional perspective, the restaurant industry is one of the fastest growing sectors in the world (Cravy, 2018). According to a global research, fast food restaurants in the United States generated $\$ 799$ billion in revenue at the end of 2017, employing over 14.7 million population, or $10 \%$ of the overall US population, and the restaurant business is anticipated to create 16.3 million jobs by 2027 . The restaurant industry in the United Kingdom generated 73.6 billion euros in earnings, followed by France with 50 billion euros, Germany with 40 billion euros, and the Netherlands with 19 billion euros (Cravy, 2018). Experts estimate that the Asia Pacific market is the fastest growing in the food service industry, with a 10\% annual growth rate adding to 1.1 trillion dollars in 2014 and 1.5 trillion dollars in sales predicted between 2015 and 2019. (Cravy, 2018). Pakistan spends more than 11.78 billion dollars yearly on eating out, according to (Islam et al., 2018), keeping it first of all developing countries.They further claim that the State Bank of Pakistan estimates that Pakistanis spend about $40 \%$ of their income on ready-to-eat meals. This means that the fastest-growing restaurant industry not only engages millions of people, but it also contribute to the economic engine and has a positive impact on other associated industries, resulting in even more economic growth (Shahzadi et al., 2018). It's also worth noting that, as the number of restaurants has increased at an exponential rate, restaurant competition has intensified. Despite the presence of a large number of dedicated customers, a large share of restaurant clientele is value competitive (Islam et al., 2018). Customers want the most bang for their buck and are continually on the lookout for more cost-effective options. In such a competitive environment, The consumer is said to be the most important aspect of a business that influences and assesses the restaurant's quality and image. The customer is the most significant marketing tool that influences and assesses the quality and image of the restaurant, according with customer is the most important marketing tool that influences and assesses the quality and image of the restaurant (Kukanja, 2014). Customers' restaurant factors are considered to be impacted by a number of things. These include both tangible and intangible aspects of a customer's eating experience, such as service quality, food kind and quality, a restaurant's location, status, and ambiance (Pedraja \& Yagüe, 2001). Existing restaurant literature, on either hand, reveals that the significance of many criteria in consumer restaurant selection varies, and it is based on the precise incentives that drive a person to visit a restaurant (Akbar \& Alaudeen, 2012; Alonso et al., 2013; Tichaawa \& Mhlanga, 2018). 


\subsection{Service Quality}

According to Kotler \& Armstrong (2011), service is a saleable activity, benefit, or satisfaction that is essentially intangible and does not result in ownership of something. Intangibility, heterogeneity, and inseparability - three well-documented properties of services-must be acknowledged for a thorough understanding of services, according to Parasuraman et al. (1985).

Quality of service Because services are performances rather than goods, they fall under the category of intangibility. Objects, precise production standards for consistent quality can be hard to come by Most services cannot be numbered, measured, inventoried, tested, or validated prior to sale to ensure quality. The quality of a service varies a lot from one producer to the next, and from one client to the next. customer, as well as day-today leadership heterogeneity Various authors have defined quality in various ways. In 1979, to Crosby Suarez et al. (1992), Quality is defined as compliance to a set of requirements, and it can be present or absent. Juran in the year 1998 Quality is defined as "fitness for usage" Suarez et al. (1992). He emphasizes the importance of striking a balance between product and service. qualities and items that are devoid of flaws. Parasuraman et al. (1985) proposed three underlying themes on service quality, which is more difficult for consumers to evaluate than goods quality, after reviewing literature on services. Style, hardness, color, label, feel, package, and fit are all tangible cues that buyers use to determine quality when purchasing something. When it comes to purchasing services, there are less clear indicators. In most cases, tangible evidence is limited to the service provider's actual facilities, equipment, and personnel..

1. Consumer expectations are compared to actual service performance to determine service quality perceptions.

2. Consumer expectations are compared to actual service performance to determine service quality perceptions.

3. Quality assessments are not just based on the outcome of a service; they also include evaluations of the service delivery process.

\subsection{Customer satisfaction}

Other than service quality, there are other factors that influence customer satisfaction in a fast food establishment. Consumers evaluate service value by weighing service quality against cost. The cost of service is essentially what customers must forego or suffer in order to acquire a desired service. It would have a negative influence on consumer perceptions of service value since it has a negative impact on consumer budgets. It can be both monetary and non-monetary in nature, such as location, travel time, and so on (Lee \& Ulgado, 1997). Furthermore, Qin \& Prybutok (2009) found that meal quality and pricing had an impact on customer satisfaction as per literature.

According to the literature review, numerous studies on service quality and customer satisfaction have been conducted in a variety of fields, including banking (Naeem \& Saif, 2010), fast food restaurants (Qin \& Prybutok, 2009), financial services (Maddern et al., 2007), health care (Markovic et al., 2014), and railway platforms (Geetika \& Nandan, 2010) in diaspora (Tan et al., 2019), in different countries in the world namely; Pakistan (Naeem \& Saif, 2010), the United Kingdom (Maddern et al., 2007), India (Geetika \& Nandan, 2010), in China (Tan et al., 2019), in Indonesia (Sumaedi \& Yarmen, 2015), in Macau (Wu \& Hsu, 2012) and in Nigeria (Salami \& Ajobo, 2012).

\subsection{Over view of MNC in Pakistan}

1. McDonald's: One of the most notable inexpensive food chains on the planet and one that is as yet growing is McDonald's. The principal outlet was dispatched in 1988 in Lahore and before long opened in Karachi seven days after. MacDonald's has 71 locations in Pakistan, spread across 24 cities, as of 2020. The outlets for McDonalds are present in more than 120 countries and the financial performance or profit from those regions is up to $20 \%$ of total of the growth in revenues Middle East/Africa is $6 \%$ and its expansion is still on its way.

2. KFC (Kentucky Fried Chicken): KFC dispatched its central command in Pakistan It started in Karachi in 1997 and now has 92 locations around the country by 2020. It is the second most driving cheap food chain in Pakistan as well as in India having opened its entryways everywhere in the nation from a sweeping menu of singed chicken, burgers and flavorful sauces. KFC is and has been serving food with quality and taste all around the globe since the start. It is considered as the oldest and the leading fast-food restaurant in Pakistan like McDonald's it is famous due to its taste and quality and its image in the country its existence is worldwide and having the all its products in reliable quality and considered as the second biggest chain for fast food in Pakistan. Companies decide to set the products according to the customers so, design of the products are influenced by the need of customers, KFC menu is going to be enriched due to the customers from chicken to the beverages. 
3. Pizza Hut: In 1958, two siblings opened one of the most well-known and famous pizza joints in the city. and it is having 74 operational outlets in Pakistan countrywide. This was Pizza Hut which is one of the primary famous pizza joints dispatched in Pakistan and stays well known till this day. Pizza Hut currently has a particularly enormous menu being served in Pakistan, beginning from various flavors and fixings, right to various kinds of outsides.

4. Domino's: Dominos Pizza was founded in Michigan, United States, and was previously known as Dominick's Pizza.. Dominos have now taken Pakistan in 2004 with a storm by being one of driving pizza puts here, having different branches everywhere in the nation. Dominos like pizza is a house of pizza or palace for the pizza like pizza hut it is famous for its specialized chain for the pizza in the Pakistan its existence is in the almost all the metropolitan cities of the Pakistan as well as famous worldwide like KFC and McDonald's it is not found in the all-major cities of Pakistan its prices also vary for the different products and sizes of the product.

5. Burger King: Burger King initially opened their entryways in Pakistan in October 2013, and from that point forward have spread all around the nation at a quick movement and Their menu comprises different sorts of burgers, fries and plates of mixed greens. Burger King has everything on their menu to fulfill a cheap food fan. Burger King is very new in Pakistan in comparison with the other fast-food chain in opposite like KFC which is the oldest one in the Pakistan instead it's a very popular and one the leading multinational fast-food chain in the Pakistan as well as in the world.

6. Localization of MNC: The culture is the most fundamental cause of a person's actions and desires (Kotler et al., 1996) "Culture is the most basic cause of a person's interests and behavior," according to Kotler et al. (1996). Herrmann \& Datta (2006) also asserted that when a company is doing planning to for the marketing strategies across the borders, culture is the most important thing to consider for MNC because every customer behave according to his culture. Impact of culture on consumer behavior like personal, psychological factors and social factors. So consideration of culture is very much important for the multinationals for doing business cross the border as these factors are influencing markets. By considering all these factors companies will be able to the strong decision making strategy that is the marketing mix. The model is shown below:

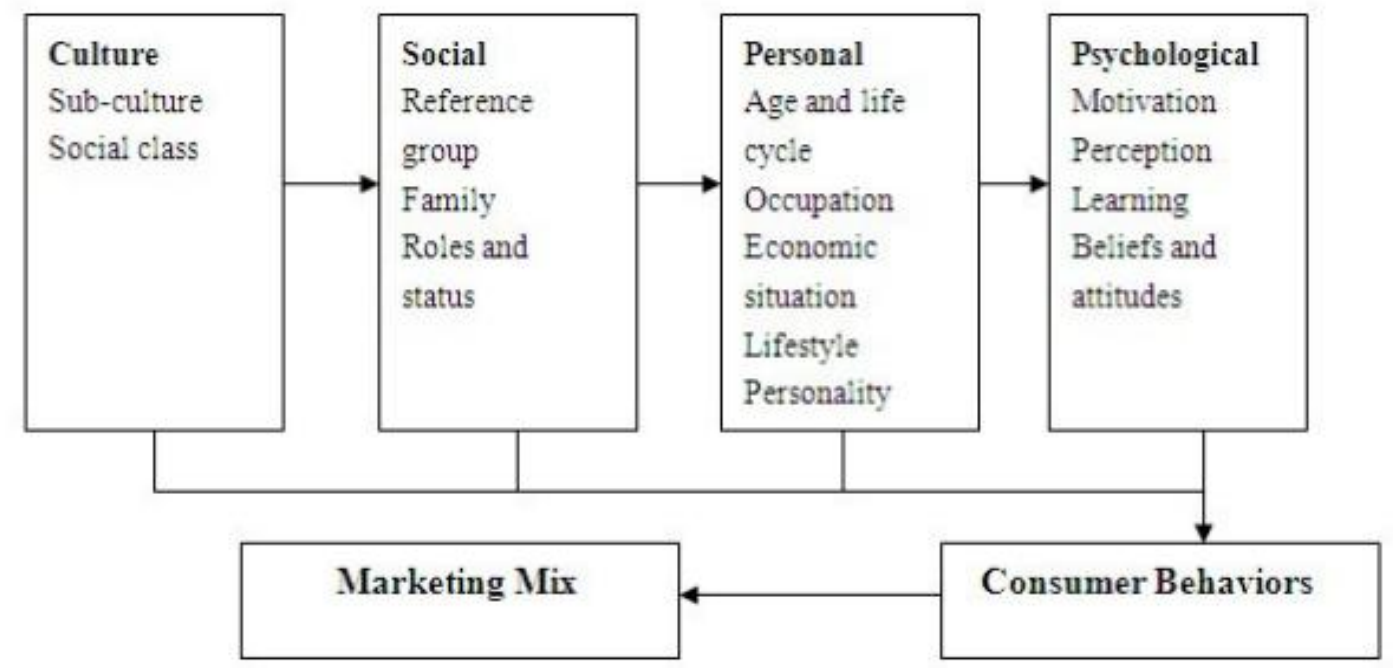

Figure 1. (Source Kotler et al. 1996)

Variables that are used for the decision making in marketing are those variables which are under the control of the companies as being components of the marketing mix through which product demand can be affected. They are somehow different from other variable like competitive and environmental actions variables which cannot be considered as being controlled by the organization itself (Kotler, 1992). Price variables, Promotion variables, Product variables, and Place variables are the four marketing assessment variables described by McCarthy (1975): Price, as well as deals and allowances, retailer mark-ups and distribution, and how the discount is arranged are all factors to consider. When taking the Product: quality, sizes \& models, service, packaging \& brands. Promotion: sales promotion, advertising, personal selling and publicity. Product or service offering, Place: Distribution channels, retail locations, sales regions, and the warehousing system are all examples of places. However, the 4Ps mix has come under growing fire, resulting in other marketing mixes being proposed for diverse marketing circumstances. 


\subsection{Culture}

"That complicated whole which encompasses knowledge, belief, art, morals, law, conventions, and other capabilities an individual develops as a member of society," writes (Tylor, 1871). Culture, according to Hofstede \& Bond (1984), is "the collective programming of the mind that separates members of one human group from members of another." Culture, according to Namenwirth \& Weber (1987), is "a system of ideas" that constitutes "a blueprint for living." According to Hill (2003), culture is a system of shared values and customs among a group of people that, when considered together, represent a design for living. Culture, according to Schaefer \& Lamm (1994), is not static, but rather spreads from group to group or society to society, a process sociologists refer to as "diffusion." Cultural meaning passes from the culturally formed environment to consumer goods, and then to the individual consumer, according to Lawson et al. (2003).

\subsection{Aim Of Study}

The aim of this research is to gain a comprehensive understanding of customer perceptions of multinational corporations (MNCs). \& consumer preference of fast food outlets in comparison of local fast food restaurants in Pakistan. Individuals are getting more mediocre with changes in unfamiliar thoughts. During the previous not many decades, the assortment in each part of life has been expanding, particularly in the food business. The point of this investigation is to comprehend the significant reasons for value changes for the comparative items in various nations. There are a few characteristics that recognize organizations with quickened worldwide development from nation to nation and to comprehend the components at significance of MNC and local food chain in Pakistan.

This study will bring out the better understanding of perception of consumers towards the MNC and local fast food chain and future growth of MNC in Pakistan.

\section{Methodology}

Area of study: study is conducted in Pakistan. Sample Size: sample size for conducting this study is 400+. Research Instrument: Open ended questionnaire Method. Sample Design: convenient for sampling method. Data sources: both primary and secondary data sources are used. Primary data is collected from fast food consumer through questionnaire survey, and secondary data by reviewing article, internet, books and magazines. Statistical tool: percentage analysis \& (SPSS)

Data is gathered from fast food customers, and information is gathered from a variety of restaurants around the world. In Pakistan, distinct primary communities were chosen. A total of 412 people were picked at random from a pool of internationally varied eateries. Both apparent and likert scale elements play a role in estimating size. Individuals who were frequent fast food customers and visited restaurants on a regular basis were the target population. KFC, Pizza Hut, McDonald's, Burger King, and Domino's Pizza are among the top global diverse MNC restaurants with customers. Simple percentage analysis is used to analyze the data collected. Consumer preferences and levels of satisfaction with MNCs in Pakistan were studied using percentage analysis and descriptive statistics.

\subsection{Simple percentage Analysis}

1. Classification on the basis of demographics

$\begin{array}{ccc}\text { Table } 1 . & \text { Classification on the basis of } & \text { demographics } \\ \text { Gender } & \text { No: of responses } & \text { Percentage } \\ \text { Male } & 262 & 63.6 \% \\ \text { Female } & 150 & 26.4 \% \\ \text { Total } & 412 & 100 \% \\ & \text { (Source: primary data) } & \end{array}$

According to the table, 63.6 percent of the 412 respondents were men and 26.4 percent were women. The majority of the respondents (63.6\%) were men.

Table 2. Classification on the basis of demographics

$\begin{array}{ccc}\text { Age } & \text { No: of responses } & \text { Percentage } \\ 16-25 & 202 & 49 \% \\ 26-35 & 157 & 38.1 \% \\ 36-45 & 39 & 9.5 \% \\ 46-55+ & 14 & 3.4 \% \\ \text { Total } & 412 & 100 \%\end{array}$

(Source: primary data) 
Table The information was acquired from 4 different age groups out of 412 responses, and it displays the respondents' age. 49 percent are between the ages of 16 and 25, 38.1 percent are between the ages of 26 and 35 , 9.5 percent are between the ages of 36 and 45, and only 3.4 percent are between the ages of 46 and 55 . The majority of those who contributed were between the ages of 16 and 25.

Table 3. Classification on the basis of demographics

$\begin{array}{ccc}\text { Occupation } & \text { No: of responses } & \text { Percentage } \\ \text { Student } & 190 & 46.1 \% \\ \text { Professional } & 172 & 41.7 \% \\ \text { Unemployed } & 32 & 7.8 \% \\ \text { Business man } & 18 & 4.4 \% \\ \text { Total } & 412 & 100 \%\end{array}$

(Source: primary data)

Table illustrates the respondents' occupations, which were divided into four categories: 46.1 percent were students, 41.7 percent were professionals in various sectors, $7.8 \%$ were unemployed, and 4.4 percent were business owners. The majority of those who responded $(46.1 \%)$ were students.

Table 4. Classification on the basis of demographics

$\begin{array}{ccc}\text { Marital Status } & \text { No: Of Responses } & \text { Percentage } \\ \text { Single } & 274 & 66 \% \\ \text { Married } & 138 & 34 \% \\ \text { Total } & 412 & 100 \%\end{array}$

Table 4 shows the marital status of the respondents through which we can conclude that the majority of the respondents were students and single out of the 100 percent of the total sample $34 \%$ were married.

2. Data about Consumer Perception

Table 5. Data about Consumer Perception Information about consumer
preferences

Frequent visits to Fast Food Restaurants

Accompanying Persons

Consumers' perception about visits, if restaurants were closer to them.

Preferable time of visit

Satisfaction with prices of MNC to local fast food restaurants.

Preference towards MNC to local fast food outlets
Number of responses

Given choices

Yes 360

No $\quad 52$

Total 412

Family

78

Friends 240

Business associates 28

Alone 26

All of above 40

Total 412

Strongly Disagree

Disagree

Neutral

Agree

Strongly Agree

Total

Week days

Week ends

On special occasions

All of above

Total

412

31

90

106

149

36

412

20

194

110

88

412

Strongly Disagree

Disagree

Neutral

Agree

20

32

40

205

115

412

280

132

412
Percentage \%

$87 \%$

$13 \%$

$100 \%$

$18.9 \%$

$58.2 \%$

$6.7 \%$

$6.3 \%$

$9.7 \%$

$100 \%$

$7.5 \%$

$21.8 \%$

$25.7 \%$

$36.2 \%$

$8.7 \%$

$100 \%$

$4.8 \%$

$47 \%$

$26.6 \%$

$21.3 \%$

$100 \%$

$4.9 \%$

$7.8 \%$

$9.7 \%$

$49.8 \%$

$27.9 \%$

$100 \%$

$68 \%$

$32 \%$

$100 \%$ 
Reasons for preferring MNC Fast food outlets to Local outlets.

Respondents interest for opening more MNC restaurants in Pakistan.

\section{Affordability of local restaurants to MNC outlets.}

Respondents interest to visit MNC Fast food outlets in future

Consumers perception about high quality MNC restaurant in Pakistan

Opinion about Fast Food Meal

Satisfaction with the price charged by MNC in Pakistan

Frequently visited restaurant

Price influencing selection of a particular fast food restaurant.

\begin{tabular}{|c|c|c|}
\hline Service Quality & 111 & $26.9 \%$ \\
\hline Brand name & 52 & $12.6 \%$ \\
\hline Social enjoyment & 159 & $38.6 \%$ \\
\hline Convenience & 90 & $21.8 \%$ \\
\hline Total & 412 & $100 \%$ \\
\hline Strongly Disagree & 20 & $4.9 \%$ \\
\hline Disagree & 32 & $7.8 \%$ \\
\hline Neutral & 40 & $9.7 \%$ \\
\hline Agree & 205 & $49.8 \%$ \\
\hline Strongly Agree & 115 & $27.9 \%$ \\
\hline Total & 412 & $100 \%$ \\
\hline Yes & 222 & $53.9 \%$ \\
\hline No & 190 & $46.1 \%$ \\
\hline Total & 412 & $100 \%$ \\
\hline Yes & 370 & $89.9 \%$ \\
\hline No & 42 & $10.1 \%$ \\
\hline Total & 412 & $100 \%$ \\
\hline Burger King & 20 & $4.9 \%$ \\
\hline Pizza hut & 32 & $7.8 \%$ \\
\hline Dominos & 40 & $9.7 \%$ \\
\hline McDonald's & 205 & $49.8 \%$ \\
\hline KFC & 115 & $27.9 \%$ \\
\hline Total & 412 & $100 \%$ \\
\hline speedy & 52 & $12.6 \%$ \\
\hline Easy take & 111 & $26.9 \%$ \\
\hline Hygienic & 90 & $21.8 \%$ \\
\hline Delicious & 159 & $38.6 \%$ \\
\hline Total & 412 & $100 \%$ \\
\hline Strongly Disagree & 71 & $17.2 \%$ \\
\hline Disagree & 161 & $39.1 \%$ \\
\hline Neutral & 93 & $22.6 \%$ \\
\hline Agree & 78 & $18.9 \%$ \\
\hline Strongly Agree & 9 & $2.2 \%$ \\
\hline Total & 412 & $100 \%$ \\
\hline $\mathrm{KFC}$ & 126 & $30.6 \%$ \\
\hline McDonald's & 154 & $37.4 \%$ \\
\hline Pizza hut & 108 & $26.2 \%$ \\
\hline Dominos & 24 & $5.8 \%$ \\
\hline Berger King & 412 & $100 \%$ \\
\hline Strongly Disagree & 24 & $5.8 \%$ \\
\hline Disagree & 46 & $11.2 \%$ \\
\hline Neutral & 92 & $22.3 \%$ \\
\hline Agree & 204 & $49.5 \%$ \\
\hline Strongly Agree & 46 & $11.2 \%$ \\
\hline Total & 412 & $100 \%$ \\
\hline
\end{tabular}

$87 \%$ consumers have the frequent visits towards MNC this shows the high popularity of MNC in Pakistan. Majority of the consumers are students between the age group of 16-25 years. $63.6 \%$ of the 412 respondents were men, while 26.4 percent were women. The majority of the respondents $(63.6 \%)$ were men. The majority of the respondents are single for fast food eaters, with 28 percent of the 412 participants being married and 72 percent being single. It is found that majority of the consumers prefer to go to MNC to local fast food chain. And this due to the quality of food, service quality, brand name, convenient and social enjoyment. $89 \%$ of the respondents are interested to have more restaurants in future so, MNC are having a huge potential for the expansion being $2^{\text {nd }}$ largest industry in Pakistan. Consumers are influenced by the price charged by the fast food restaurants in Pakistan. In comparison to MNC fast food chains, consumers are satisfied with the prices of local fast food establishments. McDonald's is regarded as a high-quality restaurant in Pakistan, whereas KFC is a commonly called restaurant with a budget-conscious mindset. Consumer visits increase when fast food businesses are closer to them, according to this study, demonstrating the impact of location on consumers. The 
location, quality, and level of satisfaction with MNCs' products in Pakistan impact consumer preference based on pricing.

\subsection{SPSS Statistics}

1. Statistical analysis Reliability of the Data

The data is collected through the structured questionnaire survey whichcomprise of questions of fast food preferences in terms of pricing having dependent and independent variable. According to Lai et al. (2007), Cronbach's Alpha reliability test values that exhibit internal stability between the scale of variables and their range should be 0.70 or above in order to have a reliable scale for research outcomes (Joyo \& Lefen, 2019). According to this study, The reliability has been tested through SPSS 20.0 and the value of Cronbach's alpha is 0.813. It shows the data is reliable.

2. Descriptive Statistics

Table 6. Descriptive Statistics

\begin{tabular}{|cccc|}
\hline & Mean & Std. Deviation & $\mathrm{N}$ \\
\hline Preference & 3.24 & .446 & 412 \\
Location & 3.72 & .640 & 412 \\
Quality & 3.31 & .862 & 412 \\
Satisfaction & 3.53 & .660 & 412 \\
\hline
\end{tabular}

The table 6 shows that dependent variable is preference and whereas the independent variable are location, quality and satisfaction with the $\mathrm{N}=412$ shows that location, quality and satisfaction the values of these variables leads towards agree side.

3. Correlation

Table 7. Correlation

\begin{tabular}{|ccccc|}
\hline Variable & Preference & Location & Quality & Satisfaction \\
\hline Preference & 1.000 & .590 & .284 & .415 \\
Location & .590 & 1.000 & .605 & .724 \\
Quality & .284 & .605 & 1.000 & .631 \\
Satisfaction & .415 & .724 & .631 & 1.000 \\
\hline
\end{tabular}

(source: Author's calculation)

Table shows that the Pearson correlation between preference and location is 0.590 that shows the positive strong correlation with preference, similarly the correlation between preferences on satisfaction is 0.412 which also shows the correlation between the variables, whereas the preference impact on quality is 0.248 which shows the weak correlation\& table 3.2 also shows that correlations between location and a quality is 0.605 demonstrate the strong correlation, whereas the correlation between location and satisfaction is 0.724 which shows that the positive strong correlation. And the correlations between the Quality and Satisfaction is 0.631 which also shows the strong correlation.

4. Multiple regression results

Table 8. Multiple regression results

\begin{tabular}{|cccccc|}
\hline Variable & Coefficients & t-value & p-value & VIF & Durbin Watson \\
\hline (Constant) & .108 & 15.885 & .000 & & \\
Location & .042 & 10.814 & .000 & 2.275 & \\
Quality & .028 & -2.291 & .022 & 1.799 & 1.831 \\
Satisfaction & .041 & .379 & .705 & 2.398 & \\
\hline
\end{tabular}

As per table 8 shows that the Location, Quality and Satisfaction has a positive significant relation that is $0.000,0.022$ and 0.705 respectively, this shows that the all independent variables a significant impact on preference. Autocorrelation should not be present when conducting linear regression. One of the main tests for autocorrelation Durbin-Watson test is one of the most valuable tests. Generally according to the rule, values in the normal range for the Durbin-Watson are between 1.5 and 2.5; the values which are considered to be more dangerous are when set other than this particular set of the values (Hair et al., 2012). Andaccording to this study Durbin Watson for autocorrelation test value is 1.831 which shows the positive autocorrelation. 
5. Histogram and P-p Plot
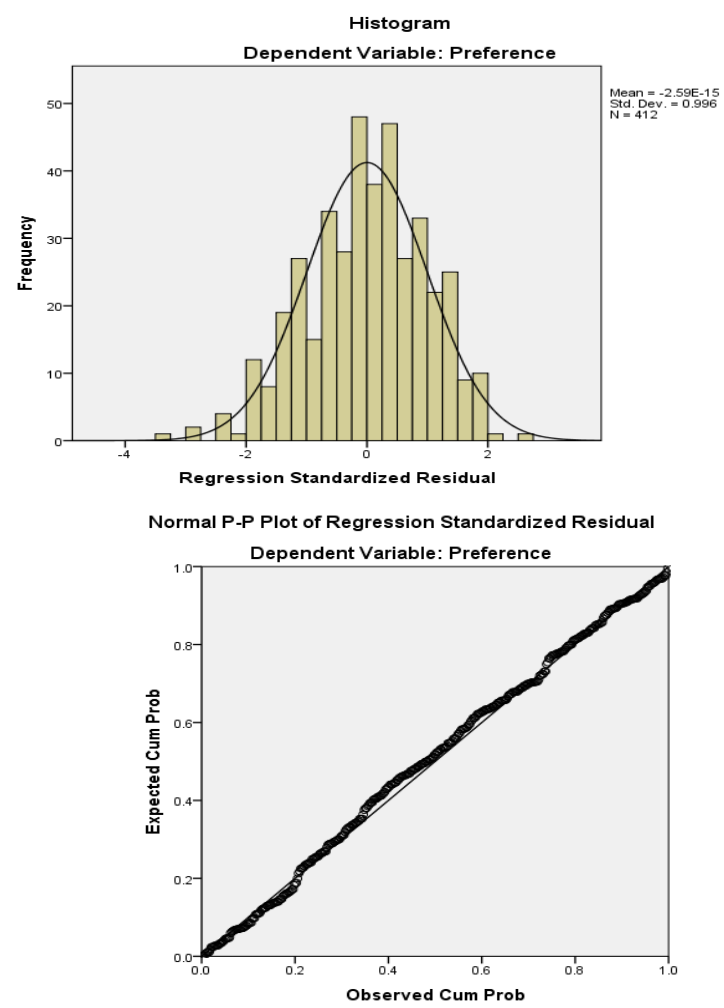

Figure 2. Histogram and P-p Plot

There are many tests available for testing the normality however, in this study normality tests have done through graphical testing with histogram and P-p plot. The figure of histogram shows that the bell shaped pattern of graph is obtained showing good fit of model and the normal distribution of the data, looking at the structure of P-p plot data points in the plot are lying closer to the diagonal line showing normal distribution of data (Pallant, 2001).

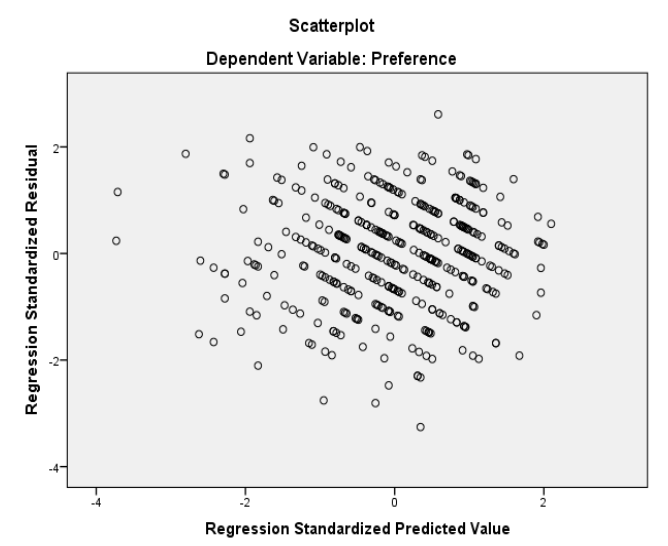

Figure 3. (Source: Author's calculation)

\section{Scatter plot}

The scatter plot in the regression model represents the values which with random displacement having rectangle shape which shows the presence of homoscedasticity \& scatter plot in this study is meeting the assumptions of the homoscedasticity and by meeting the assumptions of the homoscedasticity shows that results of the regression model are valid (Tabachnick \& Fidell, 2007).

\section{Results}

Pakistan has 1000 such units for fast food, with an approximate 185 million consumers. According to the report, McDonald's is a crucial figure in the fast-food market around the world, with 71 locations servicing millions of consumers in Pakistan's 24 major cities. On the other hand, KFC is running 92 outlets nationwide as 
of 2020.This is the second largest sales generating fast food chain in Pakistan. (Eromonitor international, 2015). The pattern of worldwide eateries however began late in Pakistan however has been fruitful due to the taste and culture of the district. The main objective for restaurants is to maintain customer satisfaction, which is mostly determined by the pricing and nature of the food they serve. Territory, cleanliness, marketing, and condition territory all play a role in shopper satisfaction. The survey's main goal is to find out how key customer loyalty is for Pakistan's global diverse eateries, as well as to figure out what customers desire to eat at their favorite multinational cafés in Pakistan. Because low-cost food ties contribute significantly to Pakistan's food sector and are an important feature of their use. An extraordinary showcase of administration quality sets up a positive effect on the customers and customer brand relationship improves which prompts client reliability. After unrivaled quality, respondents give equivalent inclination to different components, esteem for cash what's more, astounding assistance. Multinomial coordination's relapse assessment uncovers that commercial assumes the most significant part in characterizing client fulfillment for individuals living in Islamabad. Khan et al. (2020) Commercial positively affects the consumer loyalty. Focusing on clients through promoting on the online media and TV makes them mindful about the arrangements and offers going on and henceforth prompts their fulfillment. On the other hand, Locality of eateries is moderately more significant for clients in Lahore. Because the more the café is efficiently open, the more customers are pleased and visit the cafés, region has an unique and pleasant relation with client fulfillment. (Khan et al., 2020). This regular trend of fast food in Pakistan is increasing day by day in young generation specially, there many local as well as multinational corporations in Pakistan, local chains are also well known to the consumers in Pakistan including, burger, pizza, sandwiches and so many items and spend 30 to $40 \%$ of their income on the different varieties of food making this business the $2^{\text {nd }}$ largest industry of Pakistan as well as profitable and gives social enjoyment. It is revealed recently that Pakistan fast-food being $2^{\text {nd }}$ biggest industry in manufacturing sector it is providing around $15 \%$ to $18 \%$ of employment. Local fast food industry extended their stores being competent to MNC has some weaknesses of being slow in process. Larger families, children, students and youngster are frequently visiting fast food outlets specially KFC and MacDonald's at the top due to the services given in MNC and Quality of food.

This study also reveal that the prices of most of local restaurants are equal to the MNC restaurants but the consumers are fond of Pakistani food recipes so usually they prefer to go with the local food being perceived a healthy food.

\subsection{Consumer Preferences Of MNC In Pakistan}

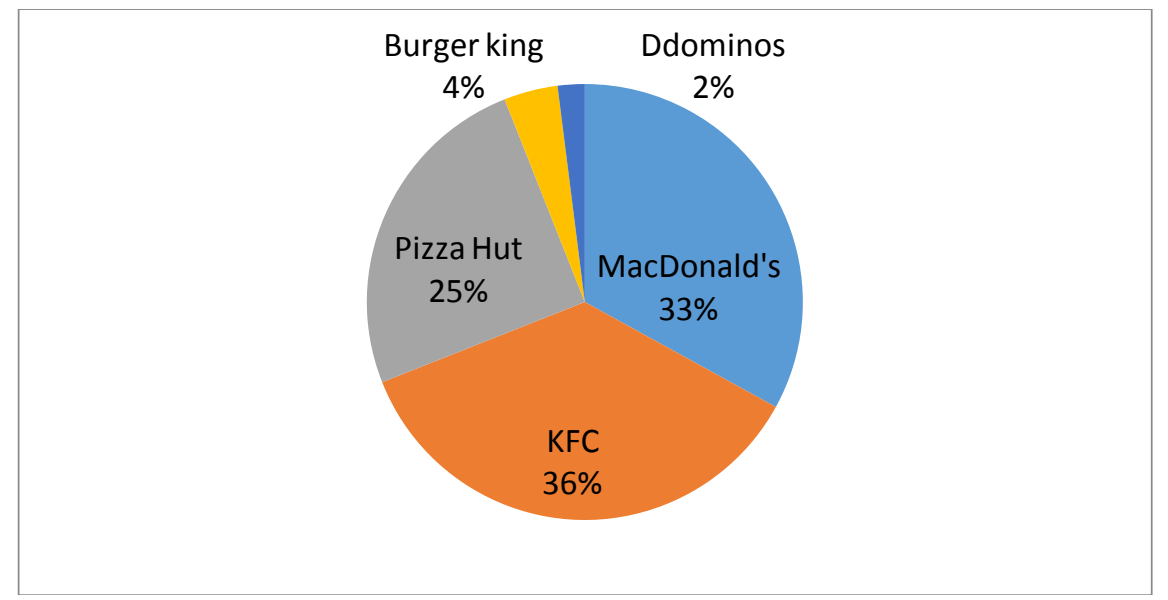

Figure 4. Fast food industry in Pakistan is increasing by 18 to $20 \%$ every year, and modernization of this industry is on its way like other developing countries and according to this study the most preferable MNC restaurant by Pakistani consumers is KFC (36\%).

\section{Suggestions}

1. Currently majority of the fast food consumers are students, MNC can improve the standard to attract the crowd

2. Consumers are from all over the Pakistan and this study found that location is the most important factor that affects the consumer frequent visits to MNC, almost all the outlets are running in metro cities of Pakistan, very few or no outlets are available in some rural areas where consumers are also fond of fast food, strategies can done for the different areas where MNC are leaving unreached of fast food to the majority of the customers.

3. Products can be improved according to the traditional taste as to increase the home delivery and to attract the consumers of all ages. 


\section{Conclusion}

Taking a look at the global challenges of rising food prices, it's clear that they're spreading to every corner of the globe. Almost every country in the globe has at least one drive-through window. McDonald's, Pizza Hut, Burger King, and KFC locations are the most exclusive. Cheap meals appears to be the ideal "allAmerican" decision, given the productive assistance, low costs, and laid-back atmosphere. McDonald's is always improving their menu items and increasing the loyalty of their customers by growing their customer base. McDonald's must diligently implement an idea related to novel thoughts into all of its activities, particularly in advertising, with the clear objective of monitoring in an extremely competitive market. McDonald's hoped to create something that would benefit them in the long run, such as long-term acceptability and an incomparable position as a "food retailer." McDonald's restricting methodology employs a global system that thinks globally while acts locally to guide its course of events. For McDonald's to attain its core aim in India, the limitation system has been absolutely vital.

For McDonald's to achieve its key vision in India, the limitation system has been absolutely essential. In view of the fact that the more effectively available the café is, the more people are satisfied and visit the cafés in Pakistan, region has a remarkable and positive link with customer satisfaction.

\section{References}

Akbar, Y. A. A., \& Alaudeen, M. S. S. (2012). Determinant of Factors that Influence Consumer in Choosing Normal Full-Service Restaurant: Case in Seri Iskandar, Perak. South East Asian Journal of Contemporary Business, Economics and Law., 1, 137-145. https://www.academia.edu/4847763/DETERMINANT_OF_FACTORS_THAT_INFLUENCE_CONSUM ER_IN_CHOOSING_NORMAL_FULL_SERVICE_RESTAURANT_CASE_IN_SERI_ISKANDAR_PE RAK

Alonso, A., Krijthe, B. P., Aspelund, T., Stepas, K. A., Pencina, M. J., Moser, C. B., Sinner, M. F., Sotoodehnia, N., Fontes, J. D., Janssens, A. C. J. W., Kronmal, R. A., Magnani, J. W., Witteman, J. C., Chamberlain, A. M., Lubitz, S. A., Schnabel, R. B., Agarwal, S. K., McManus, D. D., Ellinor, P. T., ... Benjamin, E. J. (2013). Simple risk model predicts incidence of atrial fibrillation in a racially and geographically diverse population: the CHARGE-AF consortium. Journal of the American Heart Association, 2(2). https://doi.org/10.1161/JAHA.112.000102

Baldwin, M. (2018). Scientific Autonomy, Public Accountability, and the Rise of "Peer Review" in the Cold War United States. Https://Doi.Org/10.1086/700070, 109(3), 538-558. https://doi.org/10.1086/700070

Cravy. (2018). The Restaurant Industry - A Global Perspective. Medium. https://medium.com/@CravyHQ/therestaurant-industry-a-global-perspective-26cea1b91701

Geetika, \& Nandan, S. (2010). Determinants of Customer Satisfaction on Service Quality: A Study of Railway Platforms in India. Journal of Public Transportation, 13(1), 6. https://doi.org/http://doi.org/10.5038/23750901.13.1.6

Goyal, A., \& Singh, N. P. (2007). Consumer perception about fast food in India: An exploratory study. British Food Journal, 109(2), 182-195. https://doi.org/10.1108/00070700710725536/FULL/XML

Hair, J. F., Sarstedt, M., Ringle, C. M., \& Mena, J. A. (2012). An assessment of the use of partial least squares structural equation modeling in marketing research. Journal of the Academy of Marketing Science, 40(3), 414-433. https://doi.org/10.1007/S11747-011-0261-6

Herrmann, P., \& Datta, D. K. (2006). CEO Experiences: Effects on the Choice of FDI Entry Mode*. Journal of Management Studies, 43(4), 755-778. https://doi.org/10.1111/J.1467-6486.2006.00610.X

Hill, C. W. L. (2003). Global business today (2nd ed.). McGraw-Hill Irwin. http://lib.ui.ac.id

Hofstede, G., \& Bond, M. H. (1984). Hofstede's Culture Dimensions: An Independent Validation Using Rokeach's Value Survey. Journal of Cross-Cultural Psychology, 15(4), 417-433. https://doi.org/10.1177/0022002184015004003

Islam, T., Hameed, Z., \& Sheikh, Z. (2018). The impact of self-congruity (symbolic and functional) on the brand hate: A study based on self-congruity theory. British Food Journal, 121(2), 71-88. https://doi.org/10.1108/BFJ-03-2018-0206

Joyo, A. S., \& Lefen, L. (2019). Stock Market Integration of Pakistan with Its Trading Partners: A Multivariate DCC-GARCH Model Approach. Sustainability Science, 11(2). https://doi.org/10.3390/SU11020303

Khan, A., Zia, Z., Niazi, A. K., Gillani, R., \& Malik, A. (2020). MULTINATIONAL FAST FOOD RESTAURANTS AND CUSTOMER'S SATISFACTION: A COMPARATIVE ANALYSIS OF THREE CITIES IN PAKISTAN USING MULTINOMIAL LOGIT REGRESSION. Journal of Reasearch \& Reviews Iin Social Sciences Pakistan, 3(1), 664-678. https://www.researchgate.net/publication/343852196_MULTINATIONAL_FAST_FOOD_RESTAURAN TS_AND_CUSTOMER'S_SATISFACTION_A_COMPARATIVE_ANALYYSIS_OF_THREE_CITIES_I N_PAKISTAN_USING_MULTINOMIAL_LOGIT_REGRESSION 
Kotler, P. (1992). A Perspective on the Use of Marketing Audits. Journal of Management Inquiry. https://doi.org/10.1177/105649269214006

Kotler, P., Ang, S. H., \& Tan, C. T. (1996). Marketing and Management: An Asian Perspective. In Prentice Hall. Prentice Hall. https://ink.library.smu.edu.sg/lkcsb_research/133/

Kotler, P., \& Armstrong, G. (2011). Principles Of Marketing (14th ed.). Prentice Hall.

Kukanja, M. (2014). The Quality of the Dining Experience - A Literature Overview. Academica Turistica Tourism and Innovation Journal, 7(1), 47-60. https://ideas.repec.org/a/prp/jattij/v7y2014i1p47-60.html

Lai, F., Hutchinson, J., Li, D., \& Bai, C. (2007). An empirical assessment and application of SERVQUAL in mainland China's mobile communications industry. International Journal of Quality and Reliability Management, 24(3), 244-262. https://doi.org/10.1108/02656710710730852

Lawson, N. D., Mugford, J. W., Diamond, B. A., \& Weinstein, B. M. (2003). Phospholipase C gamma-1 is required downstream of vascular endothelial growth factor during arterial development. Genes and Development, 17(11), 1346-1351. https://doi.org/10.1101/GAD.1072203

Lee, M., \& Ulgado, F. M. (1997). Consumer evaluations of fast- food services: a cross- national comparison. Journal of Services Marketing, 11(1), 39-52. https://doi.org/10.1108/08876049710158358

Maddern, H., Maull, R. S., Smart, P. A., \& Baker, P. (2007). Customer Satisfaction and Service Quality in UK Financial Service. Accepted for Inclusion in the International Journal of Production and Operations Management. https://business-school.exeter.ac.uk/documents/papers/management/2007/0710.pdf

Markovic, S., Loncaric, D., \& Loncaric, D. (2014). Service quality and customer satisfaction in the health care industry - towards health tourism market. Tourism and Hospitality Management, 20(2), 155-170. https://doi.org/10.20867/THM.20.2.1

McCarthy, E. J. (1975). Basic marketing : a managerial approach (5th ed.). Homewood. https://www.worldcat.org/title/basic-marketing-a-managerial-approach/oclc/1297702

Naeem, H., \& Saif, M. I. (2010). Employee empowerment and customer satisfaction: Empirical evidence from the banking sector of Pakistan. African Journal of Business Management, 4(10), 2028-2031. https://doi.org/10.5897/AJBM.9000252

Namenwirth, J. Z., \& Weber, R. P. (1987). Dynamics of culture (1st ed.). Taylor and Francis. https://doi.org/10.4324/9781315512174/DYNAMICS-CULTURE-ZVI-NAMENWIRTH-ROBERTPHILIP-WEBER

Pallant, J. (2001). SPSS Survival Manual. Open University Press. https://doi.org/10.4324/9781003117407

Parasuraman, A., Zeithaml, V. A., \& Berry, L. L. (1985). A Conceptual Model of Service Quality and Its Implications for Future Research. Journal of Marketing, 49(4), 41-50. https://doi.org/10.1177/002224298504900403

Pedraja, M., \& Yagüe, J. (2001). What information do customers use when choosing a restaurant? International Journal of Contemporary Hospitality Management, 13(6), 316-318. https://doi.org/10.1108/EUM0000000005966

Qin, H., \& Prybutok, V. R. (2009). Service quality, customer satisfaction, and behavioral intentions in fast- food restaurants. Undefined, 1(1), 78-95. https://doi.org/10.1108/17566690910945886

Salami, D. C. G. E., \& Ajobo, R. T. (2012). Consumer Perceptions about Fast Food Restaurants in Asaba. Global Journal of Management and Business Research, 12(1), 74-81.

https://www.academia.edu/23169234/Consumer_Perceptions_about_Fast_Food_Restaurants_in_Asaba_C onsumer_Perceptions_about_Fast_Food_Restaurants_in_Asaba

Schaefer, R. T., \& Lamm, R. P. (1994). Sociology : a brief introduction. McGraw-Hill. https://www.worldcat.org/title/sociology-a-brief-introduction/oclc/439092123

Shahzadi, A., Hussain, M., Afzal, M., \& Gilani, S. A. (2018). Determination the Level of Knowledge, Attitude, and Practices Regarding Household Waste Disposal among People in Rural Community of Lahore. International Journal of Social Sciences and Management, 5(3), 219-224. https://doi.org/10.3126/IJSSM.V5I3.20614

Suarez, L. E., Singh, M. P., \& Rohanimanesh, M. S. (1992). Seismic response of rotating machines. Earthquake Engineering \& Structural Dynamics, 21(1), 21-36. https://doi.org/10.1002/EQE.4290210102

Sumaedi, S., \& Yarmen, M. (2015). Measuring Perceived Service Quality of Fast Food Restaurant in Islamic Country: A Conceptual Framework. Procedia Food Science, 3, 119-131. https://doi.org/10.1016/J.PROFOO.2015.01.012

Tabachnick, B. G., \& Fidell, L. S. (2007). Using Multivariate Statistics (5th ed.). Pearson. https://www.pearson.com/us/higher-education/product/Tabachnick-Using-Multivariate-Statistics-5thEdition/9780205459384.html

Tan, Q., Oriade, A., \& Fallon, P. (2019). Service Quality and Customer Satisfaction in Chinese Fast Food Sector: A Proposal for CFFRSERV Scale. Advances in Hospitality and Tourism Research, 2(1), 30-53. https://wlv.openrepository.com/handle/2436/622515

Tichaawa, T. M., \& Mhlanga, O. (2018). Muslim tourist experiences and return intention in hotels: A South 
African study. Acta Universitatis Danubius. Economica, 14(4). http://journals.univdanubius.ro/index.php/oeconomica/article/view/4621/5307

Tylor, E. B. (1871). Primitive culture (Vol. 2). Cambridge University Press. https://doi.org/10.1017/CBO9780511705960

Wu, J.-Y., \& Hsu, C.-C. (2012). Foreign direct investment and income inequality: Does the relationship vary with absorptive capacity? Economic Modelling, 29(6), 2183-2189.

https://doi.org/10.1016/J.ECONMOD.2012.06.013 